\title{
Validation of TES methane with HIPPO aircraft observations: implications for inverse modeling of methane sources
}

\author{
K. J. Wecht ${ }^{1}$, D. J. Jacob ${ }^{1}$, S. C. Wofsy ${ }^{1}$, E. A. Kort ${ }^{1}$, J. R. Worden ${ }^{2}$, S. S. Kulawik ${ }^{2}$, D. K. Henze ${ }^{3}$, M. Kopacz ${ }^{4}$, , and \\ V. H. Payne ${ }^{5}$ \\ ${ }^{1}$ Department of Earth and Planetary Sciences, Harvard University, Cambridge, MA, USA \\ ${ }^{2}$ Jet Propulsion Laboratory/California Institute of Technology, Pasadena, CA, USA \\ ${ }^{3}$ Department of Mechanical Engineering, University of Colorado at Boulder, Boulder, CO, USA \\ ${ }^{4}$ Woodrow Wilson School of Public and International Affairs, Princeton University, USA \\ ${ }^{5}$ Atmospheric Environmental Research, Lexington, MA, USA \\ * now at: NOAA Climate Program Office, Silver Spring, MD, USA
}

Correspondence to: K. J. Wecht (wecht@fas.harvard.edu)

Received: 23 August 2011 - Published in Atmos. Chem. Phys. Discuss.: 14 October 2011 Revised: 3 February 2012 - Accepted: 6 February 2012 - Published: 17 February 2012

\begin{abstract}
We validate satellite methane observations from the Tropospheric Emission Spectrometer (TES) with 151 aircraft vertical profiles over the Pacific from the HIAPER Poleto-Pole Observation (HIPPO) program. We find that a collocation window of $\pm 750 \mathrm{~km}$ and $\pm 24 \mathrm{~h}$ does not introduce significant error in comparing TES and aircraft profiles. We validate both the TES standard product (V004) and an experimental product with two pieces of information in the vertical (V005). We determine a V004 mean bias of $65.8 \mathrm{ppb}$ and random instrument error of $43.3 \mathrm{ppb}$. For V005 we determine a mean bias of $42.3 \mathrm{ppb}$ and random instrument error of $26.5 \mathrm{ppb}$ in the upper troposphere, and mean biases (random instrument errors) in the lower troposphere of 28.8 (28.7) and 16.9 (28.9) ppb at high and low latitudes respectively. Even when V005 cannot retrieve two pieces of information it still performs better than V004. An observation system simulation experiment (OSSE) with the GEOS-Chem chemical transport model (CTM) and its adjoint shows that TES V004 has only limited value for constraining methane sources. Our successful validation of V005 encourages its production as a standard retrieval to replace V004.
\end{abstract}

\section{Introduction}

Methane is the second most powerful anthropogenic greenhouse gas after carbon dioxide (Forster et al. 2007). Present day methane concentrations are $\sim 2.5$ times higher than those of the pre-industrial atmosphere (Etheridge et al., 1998). This change is presumably driven by increasing emissions, but may also reflect changes in the chemical sink (reaction with the $\mathrm{OH}$ radical) (Forster et al. 2007). The magnitude of global methane emissions is constrained within $\pm 15 \%$ by knowledge of the global sink, but the magnitudes and trends of emissions from different source types and source regions are far more uncertain (Forster et al. 2007, Denman et al. 2007). Inverse modeling of atmospheric observations has emerged over the past decade as a powerful tool to reduce these uncertainties. Most inverse studies so far have relied on surface observations (Bergamaschi et al., 2005, 2010; Bousquet et al., 2006; Chen and Prinn, 2006; Fletcher et al., 2004; Hein et al., 1997; Houweling et al., 1999; Meirink et al., 2008b) but the sparsity of the network limits the ability to resolve sources (Villani et al., 2010). A few studies have used observations from the SCIAMACHY satellite instrument over land (Bergamaschi et al., 2007, 2009; Meirink et al., 2008a). Satellite observations of atmospheric methane provide dense spatial coverage but must be carefully validated to enable inverse modeling. We use here extensive vertical profiles of methane measured from aircraft by the HIAPER Pole-to-Pole Observation (HIPPO) program over the Pacific (Wofsy et al., 2011) to characterize errors in methane retrievals from the Tropospheric Emission Spectrometer (TES) aboard the NASA Aura satellite. We show that the standard product currently available from TES is of limited utility for inverse modeling, but also validate a new 
TES product with increased vertical information and more promise.

Tropospheric methane is well-mixed, with a lifetime of about 9 yr (Denman et al. 2007). Space-borne observations of column methane require precision of $1-2 \%$ and accuracy of at least $1 \%$ for inverse modeling of methane sources (Meirink et al., 2006). Methane can be retrieved from nadir measurements of solar backscatter in the near infrared (NIR) or terrestrial radiation in the thermal infrared (TIR). NIR retrievals are sensitive to the entire tropospheric column, but their dependence on reflected sunlight precludes observations at night, over most ocean surfaces, and over most cloudy targets. NIR retrievals are available from the Scanning Imaging Absorption SpectroMeter for Atmospheric CHartographY (SCIAMACHY) for 2003-2009 (Frankenberg et al., 2011) and from the Greenhouse gases Observing SATellite (GOSAT) for 2009-present (Yokota et al., 2009).

TIR methane retrievals have limited sensitivity to the lower troposphere due to lack of thermal contrast, but they can be performed day and night, over land and ocean, and for partly cloudy scenes. Uncertainties in atmospheric temperature, surface emissivity, and spectroscopic parameters of methane and interfering gases including water vapor, $\mathrm{N}_{2} \mathrm{O}$, and HDO limit the precision of TIR methane retrievals (Worden et al., 2004; Xiong et al., 2008). The Interferometric Monitor of Greenhouse gases (IMG) aboard the ADEOS satellite was the first space-borne instrument used to retrieve tropospheric methane from the TIR (Clerbaux et al., 2003; Kobayashi et al., 1999). It was operational only from August 1996 to June 1997. The Atmospheric Infrared Sounder (AIRS) and the Infrared Atmospheric Sounding Interferometer (IASI) have provided TIR methane retrievals from 2002-present and 2007-present respectively (Crevoisier et al., 2009; Razavi et al., 2009; Xiong et al., 2008). The Tropospheric Emission Spectrometer (TES) aboard the Aura satellite was launched in July 2004 and remains operational, providing so far seven years of nearly continuous global methane retrievals. The current standard methane data product is version 4 (V004), but no validation has been published so far. A new TES methane product (V005) has recently been developed and is in the prototype stage (Worden et al., 2012). The V005 retrieval offers sensitivity lower in the atmosphere by expanding the spectral range used in the retrieval, thus increasing the value of TES methane for identifying methane sources.

Before satellite retrievals can be used for inverse modeling of methane sources, their systematic and random errors must be characterized. Previous validations of SCIAMACHY and GOSAT have used coincident observations from a limited number of ground based Fourier transform spectrometers (FTS), most of which are located in Europe and eastern North America (Dils et al., 2006; Morino et al., 2011; Sussmann et al., 2005). AIRS methane has been validated with NOAA/GMD aircraft profiles from 22 locations (Xiong et al., 2008), though mainly in a small latitudinal range over North America and not extending above $400 \mathrm{hPa}$. HIPPO provides a unique resource for satellite validation with nearcontinuous curtains of methane vertical profiles from nearsurface to $330-180 \mathrm{hPa}$ over a wide latitudinal range $\left(67^{\circ} \mathrm{S}-\right.$ $\left.85^{\circ} \mathrm{N}\right)$.

\section{Data}

\subsection{TES}

TES is in a sun-synchronous polar orbit with an equator overpass local time of $\sim 13: 45$. It makes nadir observations with a spatial resolution of 5.3 by $8.3 \mathrm{~km}^{2}$. Observations are made every $182 \mathrm{~km}$ along the orbit track. Successive orbit tracks are separated by about $22^{\circ}$ longitude. The most recent publicly available TES methane product is V004 (available at http://eosweb.larc.nasa.gov/), using spectral windows of $1292.02-1305.76 \mathrm{~cm}^{-1}(7.658-7.740 \mu \mathrm{m})$ and $1307.02-$ $1307.8 \mathrm{~cm}^{-1}(7.646-7.651 \mu \mathrm{m})$. Vertical methane profiles are retrieved using the Rodgers (2000) optimal estimation technique:

$\ln \hat{z}=\ln z_{\mathrm{a}}+\mathbf{A}\left(\ln z-\ln z_{\mathrm{a}}\right)$

where $\hat{z}$ is the retrieved vertical profile vector consisting of mixing ratios on a fixed pressure grid, $\mathbf{A}$ is the averaging kernel matrix that represents the sensitivity of the retrieved profile to the true profile $z$, and $z_{\mathrm{a}}$ is the a priori specified from the MOZART chemical transport model (CTM). The retrieval method and error characterization are described by Bowman et al. (2006). A previous version of the methane retrieval (V003) is described by Payne et al. (2009).

Figure 1 (left panel) shows a typical TES V004 averaging kernel matrix in the tropics. The sensitivity peaks in the mid-upper troposphere at 200-400 hPa. The degrees of freedom for signal (DOFS) is defined as the trace of the averaging kernel matrix and estimates the number of pieces of information in the vertical profile. TES V004 methane retrievals have 0.6-1.6 DOFS, highest over warm surfaces. In view of this limited resolution we reduce each TES vertical profile to a single representative tropospheric volume mixing ratio (RTVMR) as recommended by the TES Level 2 Data User's Guide (http://tes.jpl.nasa.gov/uploadedfiles/ TESDataUsersGuideV4_0.pdf) and described by Payne et al. (2009). The RTVMR is a tropospheric column average mixing ratio weighted by vertical sensitivity. The RTVMR approach maps the retrieved methane profile from the standard 67-level pressure grid to a four-level grid uniquely defined for each TES retrieval and consisting of points at (1) the Earth's surface, (2) the altitude of maximum sensitivity, (3) the tropopause, and (4) the top of the atmosphere:

$\hat{z}_{c}=\mathbf{M}^{*} \hat{z}$ 


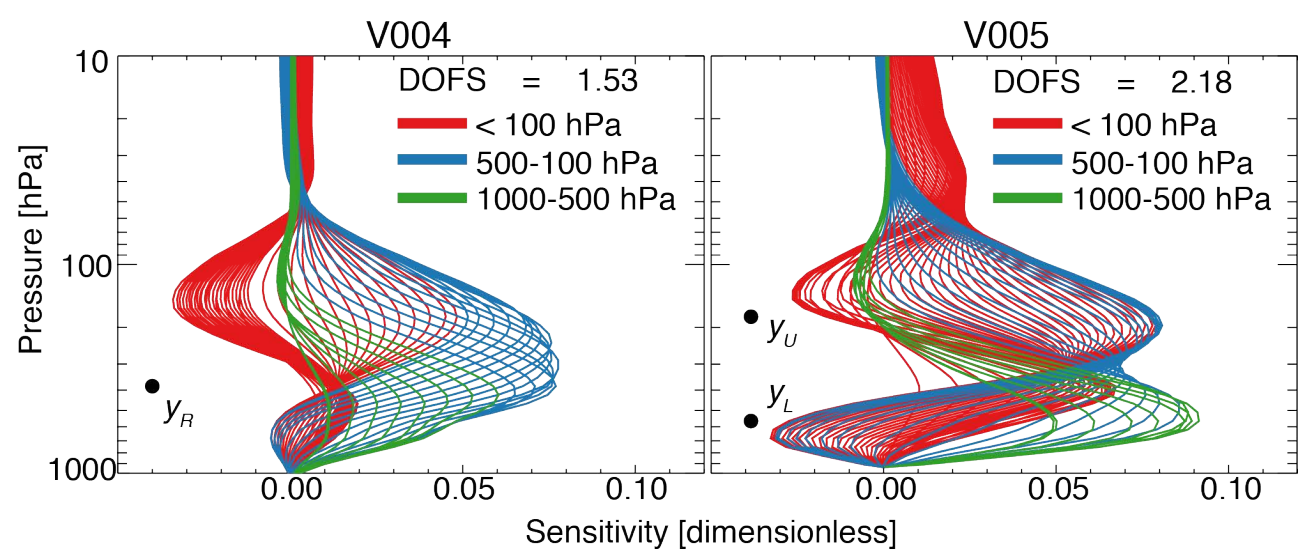

Fig. 1. Typical averaging kernel matrices for TES methane retrievals over the tropical ocean: V004 (left) and V005 (right). Data are from the same target on 7 November 2009 at $1.1^{\circ} \mathrm{S}$ and $166.9^{\circ} \mathrm{W}$. Lines are the individual rows of the averaging kernel matrix and represent the sensitivities of retrieved methane at given pressure levels to methane concentrations throughout the atmospheric column. Black circles indicate the pressure levels used for comparison to the HIPPO aircraft observations.

Here $\hat{z}_{c}$ is the TES profile on the four-level RTVMR grid, $\hat{z}$ is the TES profile on the 67-level pressure grid, and $\mathbf{M}^{*}$ is the triangular interpolation matrix that maps the fine grid onto the coarse grid. Values of $\hat{z}_{c}$ at the second lowest elevation define the RTVMR, termed $y_{\mathrm{R}}$, and represent most of the TES information. The black circle in Fig. 1 marks the pressure level associated with $y_{\mathrm{R}}$ for that particular profile.

V005 methane offers sensitivity lower in the atmosphere by expanding the spectral range of the retrieval (Worden et al., 2012), and lower systematic biases by normalizing the methane columns using simultaneously retrieved $\mathrm{N}_{2} \mathrm{O}$ columns. For this study, V005 retrievals were performed on an experimental basis along the HIPPO I and II flight paths. Figure 1 (right panel) shows the V005 averaging kernel matrix from the same target as previously shown for V004. V005 DOFS are on average 0.5 greater than for V004. Vertical sensitivities for V005 targets with DOFS $>1.6$ have two tropospheric maxima in the upper and mid troposphere, near 200 and $550 \mathrm{hPa}$ respectively. In order to capture these two pieces of vertical information, we modify the RTVMR approach for scenes with DOFS $>1.6$ by defining a five-level pressure grid onto which we map the 67-level TES retrieval. The five pressure levels are uniquely defined for each TES retrieval and are located at (1) the Earth's surface, (2) the lower tropospheric level of maximum sensitivity, (3) the upper tropospheric level of maximum sensitivity, (4) the tropopause, and (5) the top of the atmosphere. The second and third pressure levels define lower and upper tropospheric VMRs, termed $y_{\mathrm{L}}$ and $y_{\mathrm{U}}$ respectively. The black circles in Fig. 1 mark the levels associated with $y_{\mathrm{L}}$ and $y_{\mathrm{U}}$. For TES V005 scenes with DOFS $\leq 1.6$, we follow the original RTVMR approach and validate a single piece of information, $y_{\mathrm{R}}$.

\subsection{HIPPO and application of the TES Operator}

Figure 2 shows the flight paths of NSF's Gulfstream V (GV) during the first two HIPPO missions in January and OctoberNovember 2009 (HIPPO I and II respectively). The GV transected the Pacific Ocean from $85 \mathrm{~N}$ to $67 \mathrm{~S}$, performing in-progress vertical profiles every $\sim 220 \mathrm{~km}$ or 20 minutes (Wofsy et al., 2011). Methane was measured with a Quantum Cascade Laser Spectrometer (QCLS) at $1 \mathrm{~Hz}$ frequency with accuracy of $1.0 \mathrm{ppb}$ and precision of $0.5 \mathrm{ppb}$ (Kort et al., 2011). HIPPO methane data are reported on the NOAA04 calibration scale. Latitudinal curtains of the data are shown in Fig. 2. For direct comparison to TES methane we isolate each vertical profile performed by the GV, map the data on the 67 levels of the TES pressure grid, and extrapolate above the GV ceiling using the shape of the TES a priori profile. We then apply the TES observation operator to the resulting HIPPO profile, $z_{\mathrm{H}}$ :

$\ln \hat{z}_{\mathrm{H}}=\ln z_{\mathrm{a}}+\mathbf{A}\left(\ln z_{\mathrm{H}}-\ln z_{\mathrm{a}}\right)$

Here $\hat{z}_{\mathrm{H}}$ represents the profile that would have been retrieved had TES sampled the same air as HIPPO, according to the averaging kernel matrix and in the absence of other errors. We calculate $y_{R}, y_{\mathrm{L}}$, and $y_{\mathrm{U}}$ from $\hat{z}_{\mathrm{H}}$ as described earlier.

\section{TES validation}

\subsection{Approach}

TES and HIPPO profiles are not perfectly coincident in time and space. To compare the data sets, we must define an appropriate spatio-temporal coincidence window. Previous TES validation studies for tropospheric ozone with 

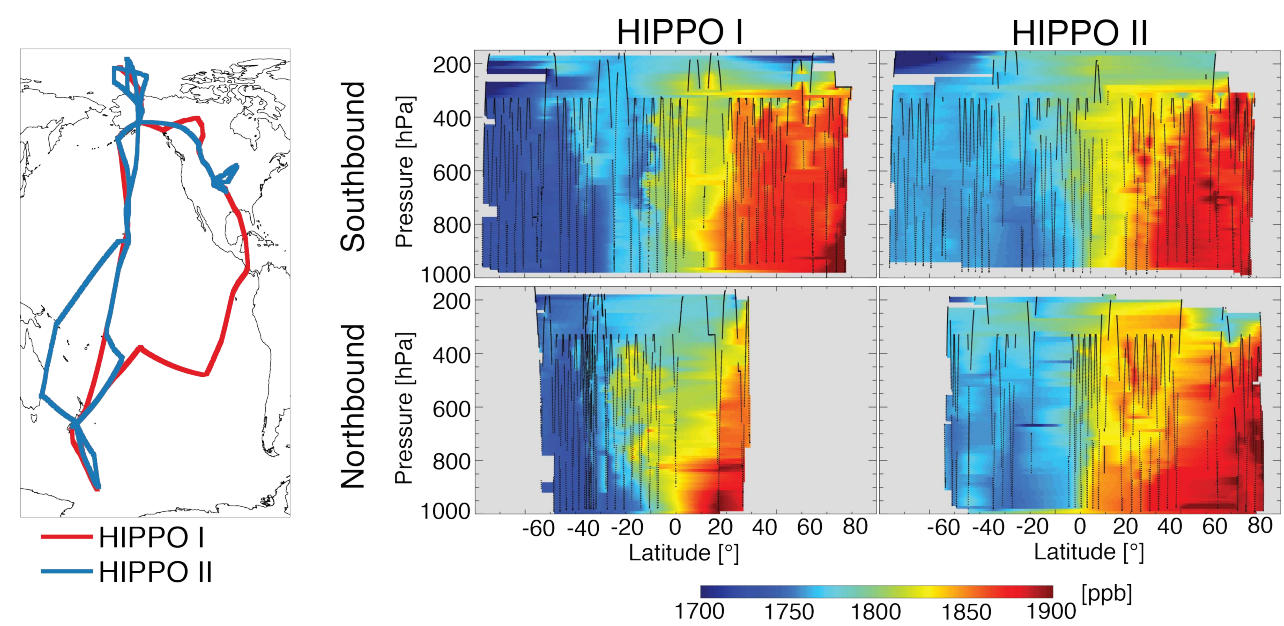

Fig. 2. The left panel shows flight paths of HIPPO missions I and II during January and October-November 2009 respectively. Center and right panels show methane concentrations as a function of latitude and pressure measured during southbound and northbound flight paths of HIPPO I and II. Black lines show the aircraft profiles with methane data. Solid contours are interpolated.

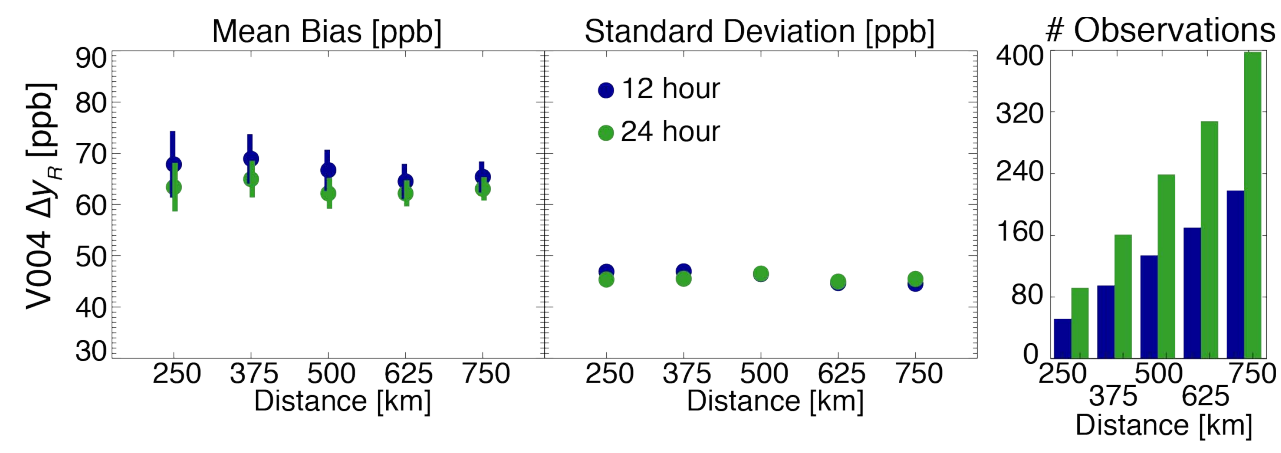

Fig. 3. Error statistics for TES V004 methane plotted as a function of the size of the coincidence window for the HIPPO I and II vertical profiles. Green and blue symbols represent coincident time windows of $\pm 24 \mathrm{~h}$ and $\pm 12 \mathrm{~h}$ respectively. Values shown are the mean value (mean bias) and residual standard deviation of the difference $\Delta y_{\mathrm{R}}$ between TES and HIPPO representative tropospheric volume mixing ratios (RTVMRs). The numbers of observations in the statistics are shown in the right panel. Error bars in the left panel represent standard errors on our estimates of the mean bias.

ozonesondes used coincidence criteria from $\pm 9 \mathrm{~h}$ to $\pm 48 \mathrm{~h}$ and $300 \mathrm{~km}$ to $600 \mathrm{~km}$ (Worden et al., 2007; Nassar et al., 2008). The high density of the HIPPO data allows an objective analysis of the collocation error and its effect on the validation constraints.

For each HIPPO vertical profile (covering $\sim 220 \mathrm{~km}$ in $\sim 20 \mathrm{~min}$ ), we calculate a mean location and time. We then find all TES observations coincident with the HIPPO profile in a specified (space, time) coincidence window. Where a single TES observation is coincident with multiple HIPPO profiles, we match it to the nearest HIPPO profile in time and space, weighting time and space equally within the coincidence window. We calculate $y_{\mathrm{R}}, y_{\mathrm{L}}$, and $y_{\mathrm{U}}$ from the TES and HIPPO profiles. From the statistics of the TESHIPPO differences, $\Delta y_{\mathrm{R}}, \Delta y_{\mathrm{L}}$, and $\Delta y_{\mathrm{U}}$, we calculate a mean TES bias (mean value of $\Delta y$ ) and residual standard deviation (standard deviation of $\Delta y$ ).
Figure 3 shows the TES V004 mean bias and residual standard deviation as a function of the size of the coincidence window. If collocation error were significant, we would expect the residual standard deviation to increase with the size of the coincidence window. This is not the case, implying that collocation error is not significant on scales up to $750 \mathrm{~km}$ and $24 \mathrm{~h}$. This may reflect the lack of fine-scale variability in the HIPPO data (Fig. 2) due to the remoteness from methane sources. We will use coincidence requirements of $750 \mathrm{~km}$ and $24 \mathrm{~h}$ in what follows, matching 151 HIPPO profiles to 398 V004 TES observations. Validation statistics are reported in Table 1 and discussed below.

\subsection{V004 validation}

Figure 4 shows the TES-HIPPO differences $\Delta y_{\mathrm{R}}$ as a function of latitude. We combine HIPPO I and II data because 
Table 1. TES V004 and V005 Methane Validation Statistics ${ }^{1}$.

\begin{tabular}{cccc}
\hline Observations & Mean Bias (ppb) & Instrument Error (ppb) & \# TES \\
\hline V004 $y_{\mathrm{R}}(65.8$ & 43.3 & 398 \\
V005 $y_{\mathrm{R}}(\mathrm{DOFS} \leq 1.6)$ & 28.7 & 24.7 & 109 \\
$y_{\mathrm{U}}$ & 42.3 & 26.5 & 280 \\
$y_{\mathrm{L}}\left(20^{\circ} \mathrm{S}-20^{\circ} \mathrm{N}\right)$ & 16.9 & 28.9 & 136 \\
$y_{\mathrm{L}}\left(>20^{\circ}\right)$ & 28.8 & 28.7 & 144 \\
\hline
\end{tabular}

${ }^{1}$ Mean biases and random instrument errors for representative tropospheric volume mixing ratios (RTVMRs) from the TES V004 and V005 retrievals. The V004 retrievals and the V005 retrievals with DOFS $\leq 1.6$ yield a single RTVMR value $y_{R}$. The V005 retrievals with DOFS $>1.6$ yield two RTVMR values, one for the upper troposphere ( $\left.y_{U}\right)$ and one for the lower troposphere $\left(y_{\mathrm{L}}\right)$, as described in the text. Mean biases and random instrument errors are obtained from TES-HIPPO difference statistics $(\Delta y)$. Mean biases for $y_{\mathrm{L}}$ are significantly different for low latitudes $\left(20^{\circ} \mathrm{S}-20^{\circ} \mathrm{N}\right)$ and high latitudes $\left(>20^{\circ}\right)$. Other error statistics do not vary significantly with latitude.

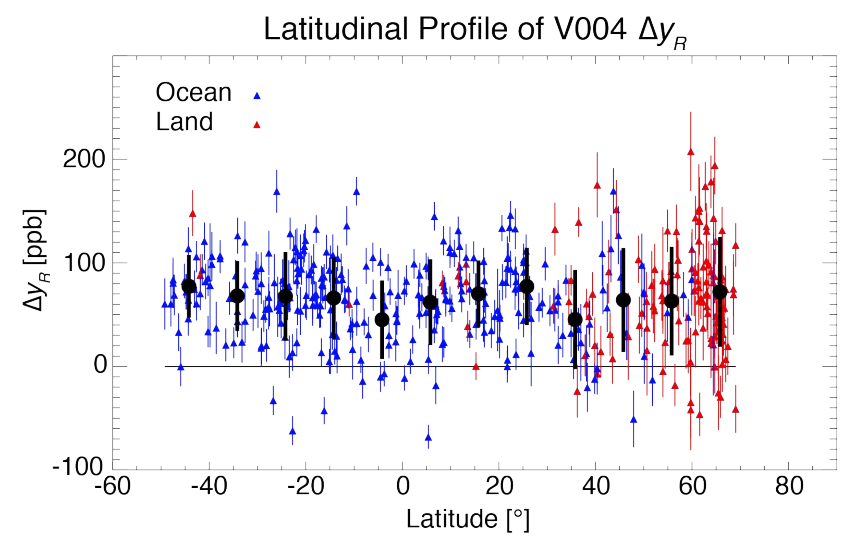

Fig. 4. Latitudinal profile of the difference $\Delta y_{\mathrm{R}}$ between TES V004 and HIPPO methane concentrations (RTVMRs) during HIPPO I \& II in January and October-November 2009. Symbols represent individual HIPPO vertical profiles, and associated vertical bars are the theoretical error standard deviations reported in the TES retrievals. Black circles and vertical bars are the means and standard deviations of $\Delta y_{\mathrm{R}}$ binned by $10^{\circ}$ latitude.

validation statistics are similar. We find a mean bias of $65.8 \mathrm{ppb}(3.7 \%)$ with a residual standard deviation of $43.8 \mathrm{ppb}(2.4 \%)$. The residual standard deviation contains contributions from random instrument error in the TES retrievals and error induced by extrapolating above the observed HIPPO profiles. We estimate the extrapolation error from the variability in upper troposphere lower stratosphere (UTLS) methane concentrations observed during HIPPO, the Airborne Southern Hemisphere Ozone Experiment (ASHOE), the Stratospheric Tracers of Atmospheric Transport (STRAT), and the Photochemistry of Ozone Loss in the Arctic Region in Summer (POLARIS) (Elkins et al., 1996; Hurst et al., 1999). From these data sets we infer negligible error in extrapolation up to the local tropopause or $200 \mathrm{hPa}$, whichever is higher, and an error standard deviation of $6 \%$ above. Using local tropopause data from the GEOS5 assimilation by the NASA Global Modeling and Assimilation Office (GMAO). We estimate an extrapolation error

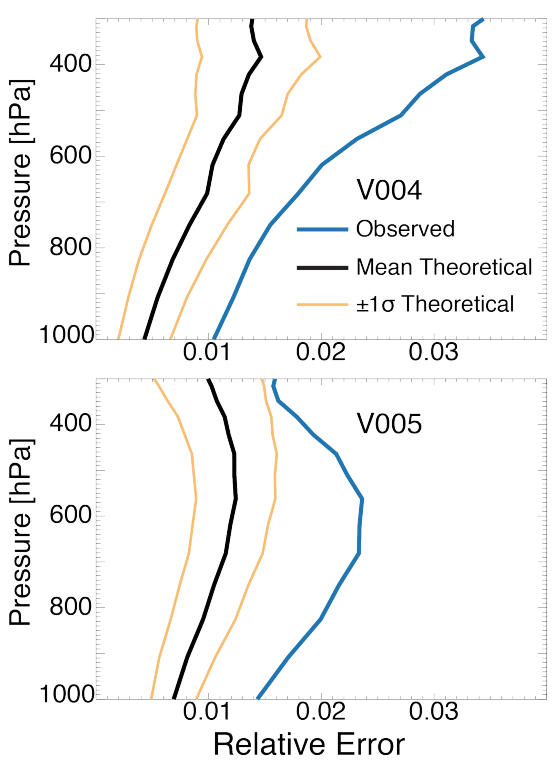

Fig. 5. Vertical profiles of V004 (top) and V005 (bottom) observed and theoretical relative errors. Blue lines represent the relative standard deviation of $\hat{z}-\hat{z}_{\mathrm{H}}$. Black and yellow lines represent the mean and standard deviation of the diagonals of the TES observation error covariance matrices.

standard deviation of $6.7 \mathrm{ppb}$, Assuming that instrument and extrapolation errors add in quadrature, we conclude that the TES instrument error is $43.3 \mathrm{ppb}(2.4 \%)$.

This TES instrument error quantified by comparison with HIPPO observations is larger than the TES V004 theoretical error of $1.1 \%$. Theoretical errors are the square roots of the diagonals of the TES self-reported error covariance matrices described by Boxe et al. (2010). Figure 5 shows the vertical structure of V004 theoretical and observed errors, the latter defined as the standard deviations of TES-HIPPO residual profiles $\left(\hat{z}-\hat{z}_{\mathrm{H}}\right)$. Observed errors are consistently higher than theoretical errors.

There is no apparent trend in $\Delta y_{\mathrm{R}}$ bias as a function of latitude. An analysis of variance (ANOVA) fails to find 


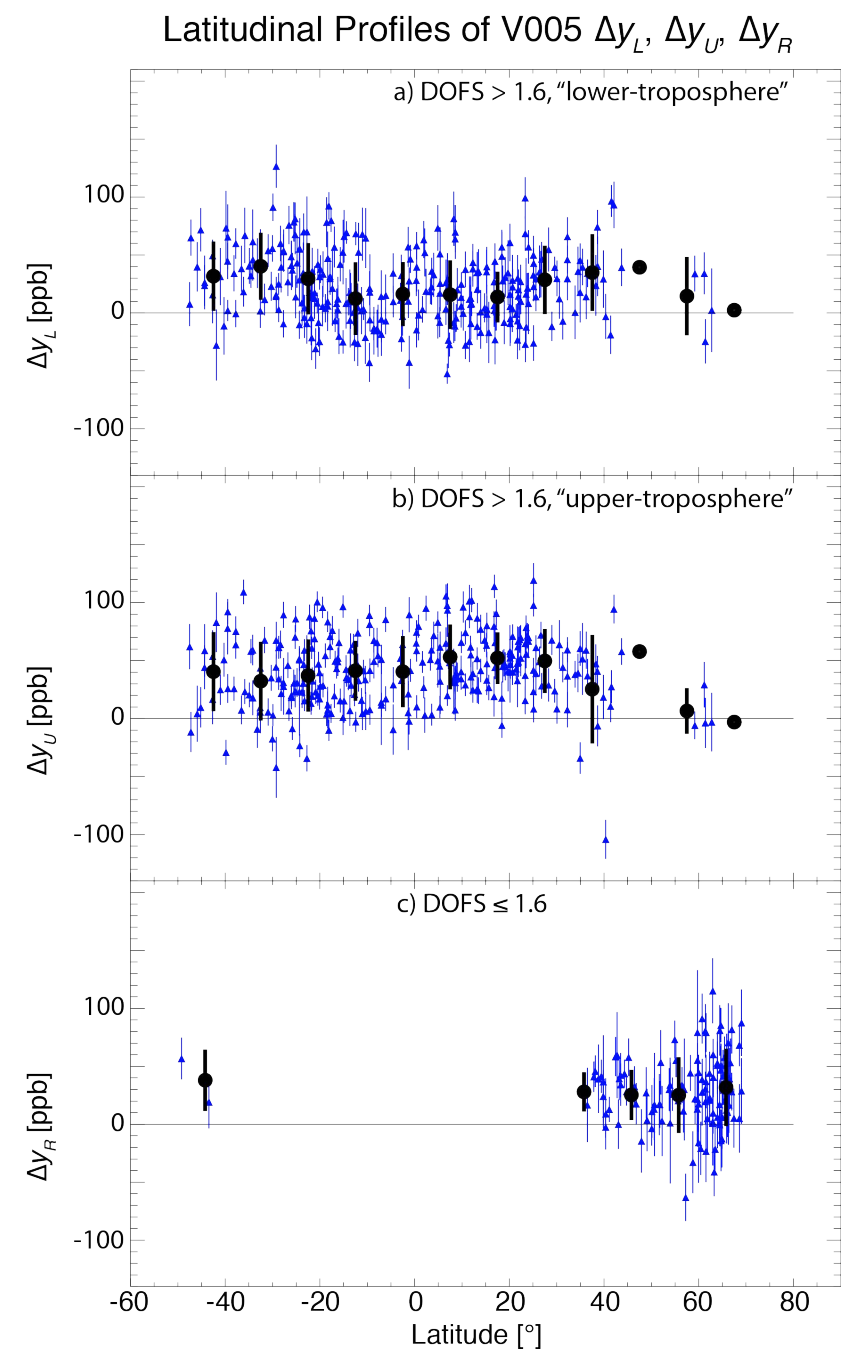

Fig. 6. Latitudinal profiles of the differences $\Delta y$ between TES V005 and HIPPO methane concentrations during HIPPO I and II in January and October-November 2009. The top two panels show results for the lower and upper tropospheric TES data $\left(\Delta y_{\mathrm{L}}\right.$ and $\Delta y_{\mathrm{U}}$, respectively) in scenes where the degrees of freedom for signal (DOFS) exceeds 1.6. The bottom panel shows results for the $\operatorname{RTVMR}\left(\Delta y_{\mathrm{R}}\right)$ in scenes where the DOFS is lower than 1.6. Blue vertical bars are the theoretical error standard deviations reported in the TES retrievals. Black circles and vertical bars are the means and standard deviations binned by $10^{\circ}$ latitude.

statistically significant differences between the mean biases in 10-degree latitude bins (Fig. 4), with a p-value of 0.80 . The standard deviation of $\Delta y_{\mathrm{R}}$ increases north of $40^{\circ} \mathrm{N}$. This trend is driven by larger $\Delta y_{\mathrm{R}}$ values over land (residual standard deviation of $52.0 \mathrm{ppb})$ than over ocean $(39.6 \mathrm{ppb})$. The mean biases of land and ocean observations are $68.4 \mathrm{ppb}$ $(3.8 \%)$ and $64.6 \mathrm{ppb}(3.6 \%)$, respectively. The biases are not statistically significantly different, with a two-sided $p$-value of 0.43 .

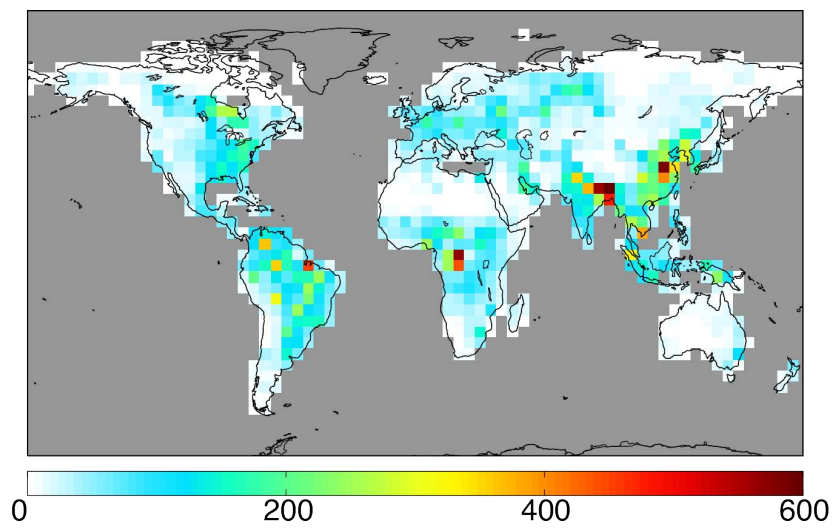

Fig. 7. Methane emissions [Mg per grid square per month] in the GEOS-Chem CTM for July-August 2008 at $4^{\circ} \times 5^{\circ}$ horizontal resolution. These are taken as the "true" emissions for the OSSE inversion of methane sources. Gray represents regions covered by ocean or ice.

\subsection{V005 validation}

Figure 6 shows the latitudinal distribution of V005-HIPPO residuals for all observations within coincidence requirements determined previously $( \pm 750 \mathrm{~km}, \pm 24 \mathrm{~h})$. The bottom panel depicts $\Delta y_{\mathrm{R}}$ comparisons for scenes with DOFS $\leq 1.6$. These show V005 $y_{\mathrm{R}}$ to be more accurate and precise than V004 $y_{\mathrm{R}}$, with a mean bias of $28.7 \mathrm{ppb}(1.6 \%)$ and residual standard deviation of $30.0 \mathrm{ppb}(1.7 \%)$. We subtract extrapolation error in the same way as before and calculate a V005 $\Delta y_{\mathrm{R}}$ instrument error of $24.7 \mathrm{ppb}(1.4 \%)$. This error is larger than the V005 self-reported $y_{\mathrm{R}}$ error of $0.8 \%$. There is no significant trend in error over the limited latitudinal range of the data.

Figure 6 top and middle panels show the latitudinal distributions of $\Delta y_{\mathrm{U}}$ and $\Delta y_{\mathrm{L}}$ for scenes with DOFS $>1.6$. There is no significant trend in $\Delta y_{\mathrm{U}}$ bias or residual standard deviation as a function of latitude. We therefore calculate a single mean bias of $42.3 \mathrm{ppb}(2.4 \%)$ with a residual standard deviation of $30.9 \mathrm{ppb}(1.7 \%)$. Removing the extrapolation error implies a TES instrument error of $26.5 \mathrm{ppb}(1.5 \%)$. There is no significant trend in $\Delta y_{\mathrm{L}}$ residual standard deviation as a function of latitude, but an ANOVA reveals that $\Delta y_{\mathrm{L}}$ mean biases in 10-degree latitude bins are marginally significantly different, with a p-value of 0.06 . We therefore report separate validation statistics for $\Delta y_{\mathrm{L}}$ at low latitudes $\left(20^{\circ} \mathrm{S}-20^{\circ} \mathrm{N}\right)$ and at high latitudes. Mean biases for low and high latitude $\Delta y_{\mathrm{L}}$ are $16.9 \mathrm{ppb}(0.9 \%)$ and $28.8 \mathrm{ppb}(1.6 \%)$, respectively. Residual standard deviations of low and high latitude $\Delta y_{\mathrm{L}}$ are $29.2 \mathrm{ppb}(1.6 \%)$ and $29.8 \mathrm{ppb}(1.7 \%)$, respectively. Removing extrapolation error implies low and high latitude $\Delta y_{\mathrm{L}}$ TES instrument errors of $28.9 \mathrm{ppb}(1.6 \%)$ and $28.7 \mathrm{ppb}$ $(1.6 \%)$, respectively.

V005 observed errors are larger than self-reported errors for $y_{U}$ and $y_{\mathrm{L}}$ of $1.0 \%$ and $0.9 \%$ respectively. Errors for 


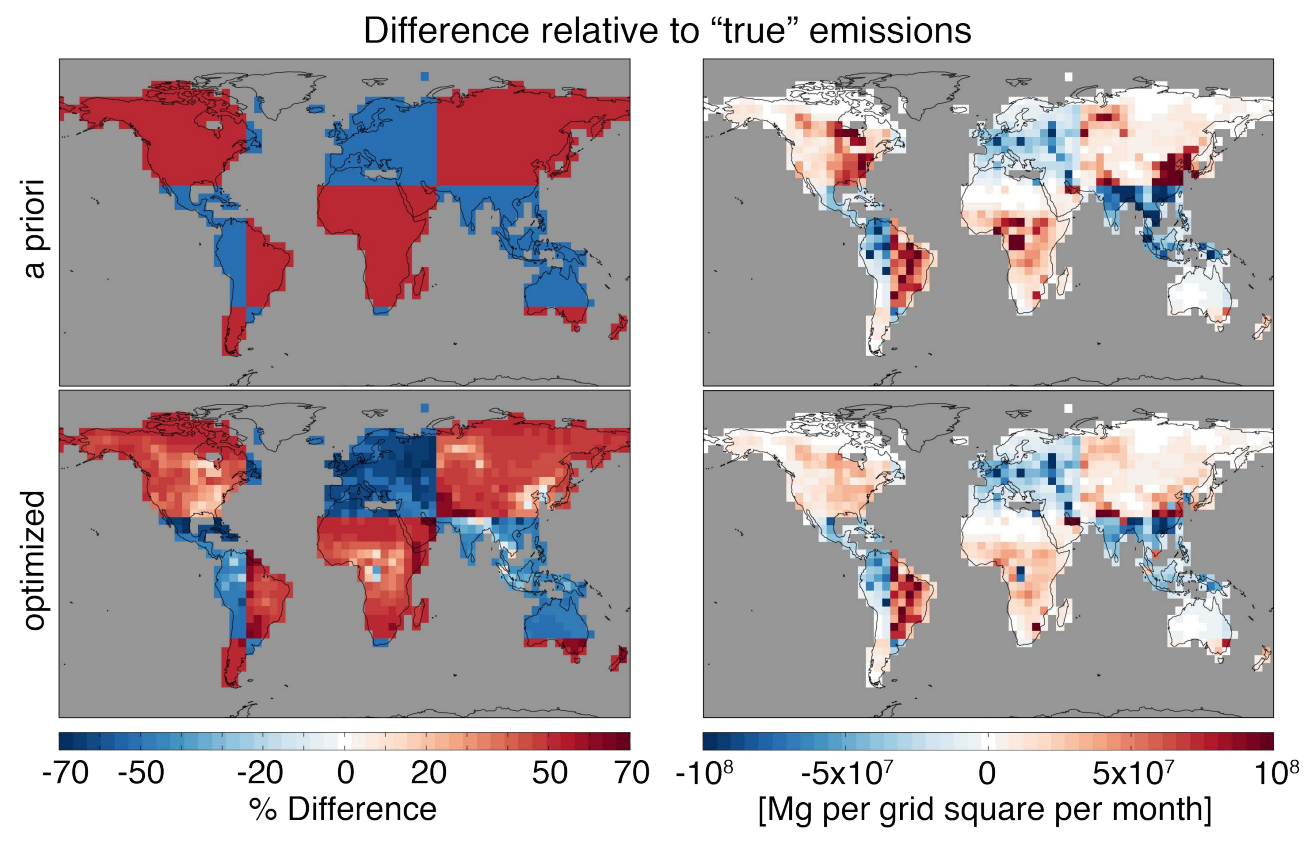

Fig. 8. Relative (left) and absolute (right) error of a priori (top) and optimized (bottom) methane emissions. Red and blue represent over and underestimates respectively. Gray represents regions covered by ocean or ice.

individual retrievals are typically larger than the theoretical error, as indicated by the error bars in Fig. 6. Figure 5 shows the vertical structure of V005 theoretical and empirical errors. Observed errors match the vertical shape of theoretical errors but are larger. This suggests that a uniform scaling of the observation error covariance matrix is needed for successful use of the V005 product for inverse modeling.

\section{Utility of TES V004 data for inverse modeling of methane sources}

We conduct here a simple observation system simulation experiment (OSSE) to evaluate the utility of the TES V004 standard methane product for constraining methane sources through inverse analysis. For this purpose we generate "true" atmospheric methane concentrations in the GEOSChem CTM (Pickett-Heaps et al., 2011) with $4^{\circ} \times 5^{\circ}$ horizontal resolution using a "true" emission distribution as shown in Fig. 7. We sample the "true" concentrations at the times and locations of TES observations, apply the TES observation operator, calculate $y_{\mathrm{R}}$, and add random Gaussian noise with standard deviation of $40 \mathrm{ppb}$, as per our validation results in Table 1. We then perturb the "true" emission distribution to produce a deliberately incorrect a priori, and assimilate the synthetic observations to generate an "optimized" emissions estimate. Comparison of the "true" and "optimized" emissions provides a measure of the utility of TES for constraining methane emissions.

We perform the OSSE for July-August 2008. There are 40600 TES observations during this period. The ensemble of synthetic observations sampling the "true" atmosphere constitutes a vector $\boldsymbol{y}_{\mathrm{O}}$ of RTVMR values. The GEOS-Chem simulation with perturbed emissions generates a corresponding model vector $y_{M}$. The "true" emissions on the $4^{\circ} \times 5^{\circ}$ grid (land only) define a state vector $\boldsymbol{x}$. The perturbed emission values represent the a priori $\boldsymbol{x}_{\mathrm{a}}$ and are increased or decreased by $50 \%$ relative to $\boldsymbol{x}$ in large blocks as depicted in Fig. 8 . We perform Bayesian optimization by minimizing the least squares scalar cost function, $J(\boldsymbol{x})$ :

$J(x)=\left(y_{\mathrm{M}}-y_{\mathrm{O}}\right)^{T} \mathbf{S}_{\mathrm{e}}^{-1}\left(\boldsymbol{y}_{M}-\boldsymbol{y}_{\mathrm{O}}\right)+\left(\boldsymbol{x}-\boldsymbol{x}_{\mathrm{a}}\right)^{T} \mathbf{S}_{\mathrm{a}}^{-1}\left(\boldsymbol{x}-\boldsymbol{x}_{\mathrm{a}}\right)$

Here $\mathbf{S}_{\mathrm{e}}$ and $\mathbf{S}_{\mathrm{a}}$ are the observational and a priori error covariance matrices, respectively. $\mathbf{S}_{\mathrm{e}}$ contains contributions from instrument, model, and representation errors. We estimate the total observational error by applying the Relative Residual Error (RRE) method to actual TES data and corresponding GEOS-Chem $\boldsymbol{y}_{\mathrm{R}}$ (Heald et al., 2004). This method attributes the temporal mean of model-observation differences for a given grid square to an error in methane emissions, and the residual to observational error. We calculate a mean $44.6 \mathrm{ppb}$ RRE for the ensemble of TES observations used in the V004 validation and use this value to populate the diagonal of $\mathbf{S}_{\mathrm{e}}$. From the residual difference between HIPPO and GEOS-Chem RTVMR, we estimate a combined model and representation error of $16.3 \mathrm{ppb}$, indicating that the observational error is principally contributed by the instrument error.

Error correlations between observations can be neglected at $4^{\circ} \times 5^{\circ}$ resolution (Heald et al., 2004), so $\mathbf{S}_{\mathrm{e}}$ is diagonal. $\mathbf{S}_{\mathrm{a}}$ is also diagonal and assigns $50 \%$ error to emissions, commensurate with the perturbation made to the "true" 


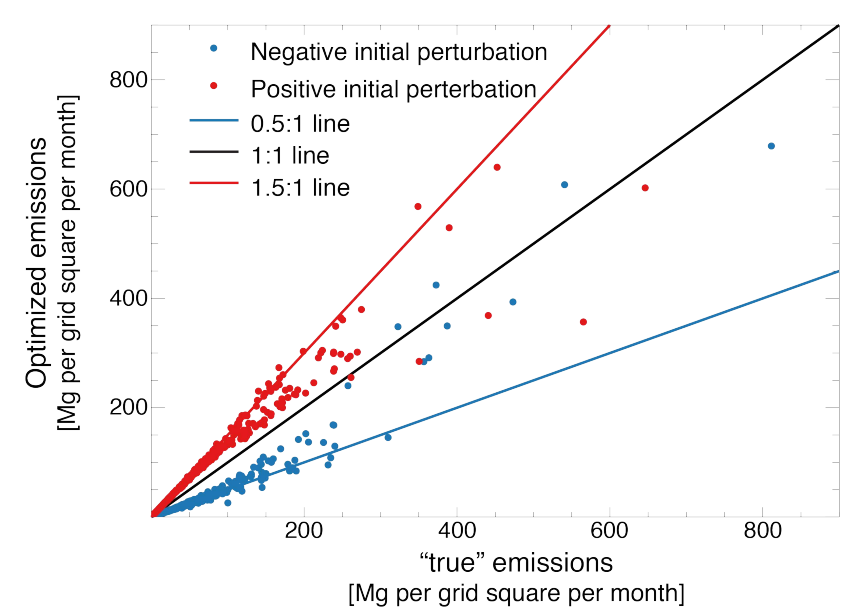

Fig. 9. Scatterplot of optimized vs. "true" methane emissions for individual $4^{\circ} \times 5^{\circ}$ grid squares. Blue and red points show emissions with negative and positive a priori perturbations, respectively. The a priori perturbations correspond to the blue and red lines.

emissions. Although the a priori errors in Fig. 8 are highly spatially correlated through the use of homogeneous perturbations in large blocks, this correlation is mainly for ease of interpretation and we would not expect such correlation in actual a priori errors. We therefore do not include error covariance terms in $\mathbf{S}_{\mathrm{a}}$.

We use GEOS-Chem and its adjoint to iteratively solve $\nabla_{x} J(\boldsymbol{x})=0$. The GEOS-Chem adjoint was developed by Henze et al. (2007) with application to CO source optimization by Kopacz et al. (2009). Our application to methane follows that for CO. The GEOS-Chem adjoint methane simulation calculates $\nabla_{x} J(\boldsymbol{x})$, and in combination with a steepest descent algorithm, iterates to find $\nabla_{x} J(\boldsymbol{x})=0$.

Figures 8 and 9 show the extent to which the optimization can correct the initially wrong a priori. TES has success for some individual $4^{\circ} \times 5^{\circ}$ grid squares with particularly large emissions and therefore large $\nabla_{x} J(x)$. In general, however, it corrects less than half of the a priori error. We conclude that V004 is only of limited value for constraining methane emissions. Considering that most of the observational error is due to instrument error, reducing that error would improve the inversion. The TES V005 data with smaller errors and higher DOFS therefore hold promise but quantitative testing must await availability of a global database of averaging kernels.

Acknowledgements. This work was supported by the US National Science Foundation under the HIPPO Program, by the NASA Atmospheric Composition Modeling and Analysis Program, and by a NASA Earth System Science Fellowship to KJW.

Edited by: M. Heimann

\section{References}

Bergamaschi, P., Krol, M., Dentener, F., Vermeulen, A., Meinhardt, F., Graul, R., Ramonet, M., Peters, W. and Dlugokencky, E.: Inverse modelling of national and European $\mathrm{CH} 4$ emissions using the atmospheric zoom model TM5, Atmos. Chem. Phys., 5, 2431-2460, doi:10.5194/acp-5-2431-2005, 2005.

Bergamaschi, P., Frankenberg, C., Meirink, J. F., Krol, M., Dentener, F., Wagner, T., Platt, U., Kaplan, J. O., Korner, S., Heimann, M., Dlugokencky, E. J. and Goede A.: Satellite chartography of atmospheric methane from SCIAMACHY on board ENVISAT: 2. Evaluation based on inverse model simulations, J. Geophys. Res., 112, D02304, doi:10.1029/2006JD007268, 2007.

Bergamaschi, P., Frankenberg, C., Meirink, J. F., Krol, M., Villani, M. G., Houweling, S., Dentener, F., Dlugokencky, E. J., Miller, J. B., Gatti, L. V., Engel, A. and Levin I.: Inverse modeling of global and regional $\mathrm{CH}_{4}$ emissions using SCIAMACHY satellite retrievals, J. Geophys. Res., 114, D22301, doi:10.1029/2009JD012287, 2009.

Bergamaschi, P., Krol, M., Meirink, J. F., Dentener, F., Segers, A., Van Aardenne, J., Monni, S., Vermeulen, A. T., Schmidt, M., Ramonet, M., Yver, C. Meinhardt, F., Nisbet, E. G., Fisher, R. E., O'Doherty, S. and Dlugokencky, E. J.: Inverse modeling of European $\mathrm{CH}_{4}$ emissions 2001-2006, J. Geophys. Res., 115, D22309, doi:10.1029/2010JD014180, 2010.

Bowman, K., Rodgers, C., Kulawik, S., Worden, J., Sarkissian, E., Osterman, G., Steck, T., Lou, M., Eldering, A., Shephard, M., Worden, H., Lampel, M., Clough, S., Brown, P., Rinsland, C., Gunson, M., and Beer, R.: Tropospheric emission spectrometer: Retrieval method and error analysis, IEEE T. Geosci. Remote, 44, 1297-1307, doi:10.1109/TGRS.2006871234, 2006.

Bousquet, P., Ciais, P., Miller, J. B., Dlugokencky, E. J., Hauglustaine, D. A., Prigent, C., Van der Werf, G. R., Peylin, P., Brunke, E. G., Carouge, C., Langenfelds, R. L., Lathiére, J., Papa, F., Ramonet, M., Schmidt, M., Steele, L. P., Tyler, S. C. and White, J.: Contribution of anthropogenic and natural sources to atmospheric methane variability, Nature, 443, 439443, doi:10.1038/nature05132, 2006.

Boxe, C.S., Worden, J. R., Bowman, K. W., Kulawik, S. S., Neu, J. L., Ford, W. C., Osterman, G. B., Herman, R. L., Eldering, A., Tarasick, D. W., Thompson, A. M., Doughty, D. C., Hoffmann, M. R., and Oltmans, S. J.: Validation of northern latitude Tropospheric Emission Spectrometer stare ozone profiles with ARC-IONS sondes during ARCTAS: sensitivity, bias and error analysis, Atmos. Chem. Phys., 10, 9901-9914, doi:10.5194/acp10-9901-2010, 2010.

Chen, Y.-H. and Prinn, R. G.: Estimation of atmospheric methane emissions between 1996 and 2001 using a three-dimensional global chemical transport model, J. Geophys. Res.-Atmos., 111, D10307, doi:10.1029/2005JD006058, 2006.

Clerbaux, C., Hadji-Lazaro, J., Turquety, S., Megie, G., and Coheur, P.: Trace gas measurements from infrared satellite for chemistry and climate applications, Atmos. Chem. Phys., 3, 1495-1508, doi:10.5194/acp-3-1495-2003, 2003.

Crevoisier, C., Nobileau, D., Fiore, A. M., Armante, R., Chedin, A. and Scott, N. A.: Tropospheric methane in the tropics - first year from IASI hyperspectral infrared observations, Atmos. Chem. Phys., 9, 6337-6350, doi:10.5194/acp-9-6337-2009, 2009.

Denman, K. L., Brasseur, G., Chidthaisong, A., Ciais, P., Cox, P. M., Dickinson, R. E., Hauglustaine, D., Heinze, C., Holland, E., 
Ja- cob, D., Lohmann, U., Ramachandran, S., da Silva Dias, P. L., Wofsy, S. C., and Zhang, X.: Climate Change 2007: The Physical Science Basis. Contribution of working group 1 to the fourth assessment report of the Intergovernmental Panel on Climate Change, chap. Changes in Atmospheric Constituents and in Radiative Forcing, Cambridge University Press, Cambridge and New York, 499-587, 2007.

Dils, B., De Maziére, M., Müller, J. F., Blumenstock, T., Buchwitz, M., de Beek, R., Demoulin, P., Duchatelet, P., Fast, H., Frankenberg, C., Gloudemans, A., Griffith, D., Jones, N., Kerzenmacher, T., Kramer, I., Mahieu, E., Mellqvist, J., Mittermeier, R. L., Notholt, J., Rinsland, C. P., Schrijver, H., Smale, D., Strandberg, A., Straume, A. G., Stremme, W., Strong, K., Sussmann, R., Taylor, J., van den Broek, M., Velazco, V., Wagner, T., Warneke, T., Wiacek, A., and Wood, S.: Comparisons between SCIAMACHY and ground-based FTIR data for total columns of $\mathrm{CO}, \mathrm{CH}_{4}, \mathrm{CO}_{2}$ and $\mathrm{N}_{2} \mathrm{O}$, Atmos. Chem. Phys., 6, 1953-1976, doi:10.5194/acp6-1953-2006, 2006.

Elkins, J. W., Fahey, D. W., Gilligan, J. M., Dutton, G. S., Baring, T. J., Volk, C. M., Dunn, R. E., Myers, R. C., Montzka, S., A., Wamsley, P. R., Hayden, A. H., Butler, J. H., Thompson, T. M., Swanson, T. H., Dlugokencky, E. J., Novelli, P. C., Hurst, D. F., Lobert, J. M., Ciciora, S. J., McLaughlin, R. J., Thompson, T. L., Winkler, R. H., Fraser, P. J., Steele, L. P., and Lucarelli, M. P.: Airborne gas chromatograph for in situ measurements of longlived species in the upper troposphere and lower stratosphere, Geophys. Res. Lett., 23, 347-350, 1996.

Etheridge, D., Steele, L., Francey, R., and Langenfelds, R.: Atmospheric methane between $1000 \mathrm{AD}$ and present: Evidence of anthropogenic emissions and climatic variability, J. Geophys. Res.Atmos., 103, 15979-15993, 1998.

Fletcher, S., Tans, P., Bruhwiler, L., Miller, J. and Heimann, M.: $\mathrm{CH}_{4}$ sources estimated from atmospheric observations of $\mathrm{CH}_{4}$ and its $\mathrm{C}-13 / \mathrm{C}-12$ isotopic ratios: 1. Inverse modeling of source processes, Global Biogeochem. Cy., 18, GB4004, doi:10.1029/2004GB002223, 2004.

Forster, P., Ramaswamy, V., Artaxo, P., Berntsen, T., Betts, R., Fahey, D. W., Haywood, J., Lean, J., Lowe, D. C., Myhre, G., Nganga, J., Prinn, R., Raga, G., Schultz, M., and Van Dorland, R.: Changes in Atmospheric Constituents and in Radiative Forcing, in: Climate Change 2007: The Physical Science Basis. Contribution of Working Group I to the Fourth Assessment Report of the Intergovernmental Panel on Climate Change, edited by: Solomon, S., Qin, D., Manning, M., Chen, Z., Marquis, M., Averyt, K. B., Tignor, M. and Miller, H. L., Cambridge University Press, Cambridge, UK and New York, NY, USA, 2007.

Frankenberg, C., Aben, I., Bergamaschi, P., Dlugokencky, E. J., van Hees, R., Houweling, S., van der Meer, P., Snel, R. and Tol, P.: Global column-averaged methane mixing ratios from 2003 to 2009 as derived from SCIAMACHY: Trends and variability, J. Geophys. Res., 116, D02304, doi:10.1029/2010JD014849, 2011.

Heald, C., Jacob, D., Jones, D., Palmer, P., Logan, J., Streets, D., Sachse, G., Gille, J., Hoffman, R., and Nehrkorn, T.: Comparative inverse analysis of satellite (MOPITT) and aircraft (TRACE-P) observations to estimate Asian sources of carbon monoxide, J Geophys Res-Atmos, 109, D23306, doi:10.1029/2004JD005185, 2004.

Hein, R., Crutzen, P., and Heimann, M.: An inverse modeling approach to investigate the global atmospheric methane cycle,
Global Biogeochem. Cy., 11, 43-76, 1997.

Henze, D. K., Hakami, A., and Seinfeld, J. H.: Development of the adjoint of GEOS-Chem, Atmos. Chem. Phys., 7, 2413-2433, doi:10.5194/acp-7-2413-2007, 2007.

Houweling, S., Kaminski, T., Dentener, F., Lelieveld, J., and Heimann, M.: Inverse modeling of methane sources and sinks using the adjoint of a global transport model, J. Geophys. Res.Atmos., 104, 26137-26160, 1999.

Hurst, D. F., Dutton, G. S., Romashkin, P. A., Wamsley, P. R., Moore, F. L., Elkins, J. W., Hintsa, E. J., Weinstock, E. M., Herman, R. L., Moyer, E. J., Scott, D. C., May, R. D., and Webster, C. R.: Closure of the total hydrogen budget of the northern extratropical lower stratosphere, J. Geophys. Res.-Atmos., 104, 8191-8200, 1999.

Kobayashi, H., Shimota, A., Kondo, K., Okumura, E., Kameda, Y., Shimoda, H., and Ogawa, T.: Development and evaluation of the interferometric monitor for greenhouse gases: a high-throughput Fourier-transform infrared radiometer for nadir Earth observation, Appl. Optics, 38, 6801-6807, 1999.

Kopacz, M., Jacob, D. J., Henze, D. K., Heald, C. L., Streets, D. G., and Zhang, Q.: Copmarison of adjoint and analytical Bayesian inversion methods for constraining Asian sources of carbon monoxide using satellite (MOPITT) measurements of CO columns, Geophys. Res., 114, D04305, doi:10.1029/2007JD009264, 2009.

Kort, E. A., Patra, P. K., Ishijima, K., Daube, B. C., Jiménez, R., Elkins, J., Hurst, D., Moore, F. L., Sweeney, C., and Wofsy, S. C.: Tropospheric distribution and variability of $\mathrm{N}_{2} \mathrm{O}$ : Evidence for strong tropical emissions, Geophys. Res. Lett., 38, L15806, doi:10.1029/2011GL047612, 2011.

Meirink, J., Eskes, H., and Goede, A.: Sensitivity analysis of methane emissions derived from SCIAMACHY observations through inverse modelling, Atmos. Chem. Phys., 6, 1275-1292, doi:10.5194/acp-6-1275-2006, 2006.

Meirink, J. F., Bergamaschi, P., Frankenberg, C., D’amelio, M. T. S., Dlugokencky, E. J., Gatti, L. V., Houweling, S., Miller, J. B., Röckmann, T., Villani, M. G. and Krol, M. C.: Four-dimensional variational data assimilation for inverse modeling of atmospheric methane emissions: Analysis of SCIAMACHY observations, J. Geophys. Res., 113(D17), D17301, doi:10.1029/2007JD009740, 2008a.

Meirink, J. F., Bergamaschi, P., and Krol, M. C.: Fourdimensional variational data assimilation for inverse modelling of atmospheric methane emissions: method and comparison with synthesis inversion, Atmos. Chem. Phys., 8, 6341-6353, doi:10.5194/acp-8-6341-2008, 2008b.

Morino, I., Uchino, O., Inoue, M., Yoshida, Y., Yokota, T., Wennberg, P. O., Toon, G. C., Wunch, D., Roehl, C. M., Notholt, J., Warneke, T., Messerschmidt, J., Griffith, D. W. T., Deutscher, N. M., Sherlock, V., Connor, B., Robinson, J., Sussmann, R., and Rettinger, M.: Preliminary validation of column-averaged volume mixing ratios of carbon dioxide and methane retrieved from GOSAT short-wavelength infrared spectra, Atmos. Meas. Tech., 4, 1061-1076, doi:10.5194/amt-4-1061-2011, 2011.

Nassar, R., Logan, J. A., Worden, H. M., Megretskaia, I. A., Bowman, K. W., Osterman, G. B., Thompson, A. M., Tarasick, D. W., Austin, S., Claude, H., Dubey, M. K., Hocking, W. K., Johnson, B. J., Joseph, E., Merrill, J., Morris, G. A., Newchurch, M., Oltmans, S. J., Ponsy, F., Schmidlin, F. J., Vmel, 
H., Whiteman, D. N. and Witte, J. C.: Validation of Tropospheric Emission Spectrometer (TES) nadir ozone profiles using ozonesonde measurements, J. Geophys. Res.-Atmos., 113, D15S17, doi:10.1029/2007JD008819, 2008.

Payne, V. H., Clough, S. A., Shephard, M. W., Nassar, R., and Logan, J. A.: Information-centered representation of retrievals with limited degrees of freedom for signal: Application to methane from the Tropospheric Emission Spectrometer, J. Geophys. Res., 114, D10307, doi:10.1029/2008JD010155, 2009.

Pickett-Heaps, C. A., Jacob, D. J., Wecht, K. J., Kort, E. A., Wofsy, S. C., Diskin, G. S., Worthy, D. E. J., Kaplan, J. O., Bey, I., and Drevet, J.: Magnitude of seasonality of wetland methane emissions from the Hudson Bay Lowlands (Canada), Atmos. Chem. Phys., 11, 3773-3779, doi:10.5194/acp-8-6365-2011, 2011.

Razavi, A., Clerbaux, C., Wespes, C., Clarisse, L., Hurtmans, D., Payan, S., Camy-Peyret, C. and Coheur, P. F.: Characterization of methane retrievals from the IASI space-borne sounder, Atmos. Chem. Phys., 9, 7889-7899, doi:10.5194/acp-9-7889-2009, 2009.

Rodgers, C. D.: Inverse Methods for Atmospheric Sounding, World Scientific Publishing Co. Pte. Ltd, Tokyo, Japan, 2000.

Sussmann, R., Stremme, W., Buchwitz, M. and de Beek, R.: Validation of ENVISAT/SCIAMACHY columnar methane by solar FTIR spectrometry at the ground- truthing station zugspitze, Atmos. Chem. Phys., 5, 2419-2429, doi:10.5194/acp-5-2419-2005, 2005.

Villani, M. G., Bergamaschi, P., Krol, M., Meirink, J. F., and Dentener, F.: Inverse modeling of European $\mathrm{CH}_{4}$ emissions: sensitivity to the observational network, Atmos. Chem. Phys., 10, 1249-1267, doi:10.5194/acp-10-1249-2010, 2010.

Wofsy, S. C.the HIPPO Science Team and Cooperating Modellers and Satellite Teams: HIAPER Pole-to-Pole Observations (HIPPO): fine-grained, global-scale measurements of climatically important atmospheric gases and aerosols, Philosoph. Trans. Roy. Soc. A: Mathematical, Physical and Engineering Sciences, 369, 2073-2086, doi:10.1098/rsta.2010.0313, 2011.
Worden, H. M., Logan, J. A., Worden, J. R., Beer, R., Bowman, K., Clough, S. A., Eldering, A., Fisher, B. M., Gunson, M. R., Herman, R. L., Kulawik, S. S., Lampel, M. C., Luo, M., Megretskaia, I. A., Osterman, G. B., Shephard, M. W.: Comparisons of Tropospheric Emission Spectrometer (TES) ozone profiles to ozonesondes: Methods and initial results, J. Geophys. Res., 112, D03309, doi:10.1029/2006JD007258, 2007.

Worden, J., Kulawik, S., Shephard, M., Clough, S., Worden, H., Bowman, K., and Goldman, A.: Predicted errors of tropospheric emission spectrometer nadir retrievals from spectral window selection, J. Geophys. Res.-Atmos., 109, D09308, doi:10.1029/2004JD004522, 2004.

Worden, J., Kulawik, S., Frankenberg, C., Bowman, K., Payne, V., Cady-Peirara, K., Wecht, K., Lee, J.-E., Noone, D., and Risi, C.: Profiles of $\mathrm{CH}_{4}, \mathrm{HDO}, \mathrm{H}_{2} \mathrm{O}$, and $\mathrm{N}_{2} \mathrm{O}$ with improved lower tropospheric vertical resolution from Aura TES radiances, Atmos. Meas. Tech. Discuss., 4, 6679-6721, doi:10.5194/amtd-4-66792012, 2012.

Xiong, X., Barnet, C., Maddy, E., Sweeney, C., Liu, X., Zhou, L. and Goldberg, M.: Characterization and validation of methane products from the Atmospheric Infrared Sounder (AIRS), J. Geophys. Res., 113, G00A01, doi:10.1029/2007JG000500, 2008.

Yokota, T., Yoshida, Y., Eguchi, N., Ota, Y., Tanaka, T., Watanabe, H. and Maksyutov, S.: Global Concentrations of $\mathrm{CO} 2$ and $\mathrm{CH} 4$ Retrieved from GOSAT: First Preliminary Results, Sola, 5, 160163, doi:10.2151/sola.2009-041, 2009. 